\title{
Perception of corruption and public support for redistribution in Latin America
}

\author{
Esther Hauk ${ }^{a}$, Mónica Oviedo ${ }^{\mathrm{b}}$, Xavier Ramos ${ }^{\mathrm{c}, *}$ \\ ${ }^{a}$ Instituto de Análisis Económico (IAE-CSIC), Move and Barcelona School of Economics, Campus UAB, 08193 Bellaterra, Barcelona, Spain \\ ${ }^{\mathrm{b}}$ UPF \& EQUALITAS, Escola Superior de Ciències Socials i de l'Empresa, TecnoCampus, UPF, 08302 Mataró, Barcelona, Spain \\ c UAB, IZA \& EQUALITAS, Department Economia Aplicada, Facultat d'Economia i Empresa, Campus UAB, 08193 Bellaterra, Barcelona, Spain
}

\section{A R T I C L E I N F O}

\section{JEL classification:}

D31

D63

D73

H1

$\mathrm{H} 2$

P16

Keywords:

Preference for redistribution

Corruption perceptions

Political trust

Bribery

Latin America

\begin{abstract}
A B S T R A C T
This paper studies the relationship between people's beliefs about the quality of their institutions, as measured by corruption perceptions, and preferences for redistribution in Latin America. Our empirical study is guided by a theoretical model which introduces taxes into Foellmi and Oechslin's (2007) general equilibrium model of non-collusive corruption. In this model perceived corruption influences people's preferences for redistribution through two channels. On the one hand it undermines trust in government, which reduces people's support for redistribution. On the other hand, more corruption decreases own wealth relative to average wealth of below-average-wealth individuals leading to a higher demand for redistribution. Thus, the effect of perceived corruption on redistribution cannot be signed a priori. Our novel empirical findings for Latin America suggest that perceiving corruption in the public sector increases people's support for redistribution. Although the wealth channel dominates in the data, we also find evidence for the trust channel - from corruption to demand for redistribution via reduced trust.
\end{abstract}

\section{Introduction}

Political support for redistribution from the rich to the poor is a cornerstone in the design and functioning of the social contract and the stability of welfare systems. However, if corruption in the public sector is widespread, welfare states are not efficient and well-functioning. Corruption may distort the redistributive role of government by mis-targeting redistributive programs or favouring special interests (Tanzi and Davoodi, 1998; Mauro, 1998; Rose-Ackerman, 1999; Gupta et al., 2002; Bird et al., 2008).

Corruption also influences the demand for redistributive policies, both at the individual and collective level. By distorting the redistributive role of government, corruption creates more inequality, deepening the need and perhaps the demand for further redistribution, and also erodes trust in government, which may undermine public support for redistributive policies. Furthermore, in countries with high inequality, where redistributive policy matters most, rich individuals can use their financial capacity to pay poor individuals to vote against high taxes (Docquier and Tarbalouti, 2001; Acemoglu et al., 2011; Balafoutas, 2011). This votebuying distorts collective demand for redistribution. Therefore, implemented distributional policies like the size or the generosity of the welfare state do not necessarily reflect people's true individual demand for redistribution. ${ }^{1}$

\footnotetext{
* Corresponding author.

E-mail addresses: esther.hauk@iae.csic.es (E. Hauk), mjoviedo@tecnocampus.cat (M. Oviedo), xavi.ramos@uab.cat (X. Ramos).

1 A recent paper that studies the link between corruption and observed redistribution is Sanchez and Goda (2018). Studying 148 countries and using the antiquity of the state and the complexity of the judicial system as instruments they find a negative effect of corruption as measured by Transparency International's corruption perception index on the real size of the welfare state. They acknowledge that this result does not allow to establish which mechanisms are at play.
} 
Systematic opinion surveys have opened the door to study the link between perceived corruption and the demand for redistribution at the micro-level avoiding confounding factors in aggregate demand and supply measures. The present paper attempts to clarify how perceived corruption influences individual demand for redistribution in 18 countries in Latin America using data from the AmericasBarometer survey and provides causal evidence that overall individual demand for redistribution increases with perceived corruption. ${ }^{2}$

Latin America is of special interest for a variety of reasons. It is a region featuring very high and persistent inequality levels not only in terms of income inequality but the region also exhibits the world's most unequal distribution of development outcomes, such as educational achievement, land ownership, and access to the formal labour market. (World Bank, 2006; Goñi et al., 2008; OECD, 2009; Rodríguez-Castelán et al., 2016). Institutions in Latin America tend to be weak and are plagued by high levels of corruption (Transparency International, 2020; Kaufmann et al., 2009). Moreover, redistributive policies vary widely in Latin America even among countries with similar levels of inequality ${ }^{3}$ and are not effective at reducing economic disparities. ${ }^{4}$ It is also a region with important credit constraints since credit market imperfections are widespread in "poorer countries" (Galindo and Schiantarelli, 2003; Levine, 1997). Last but not least, Latin America is sufficiently different from the average OECD country that findings for OECD countries might not extend to this region. Using our LAPOP sample, we find evidence that Latin America is different both for the link between corruption and individual demand for redistribution and its link to the actual size of the welfare state. While in OECD countries non-civic individuals, who find it acceptable to cheat on taxes and abuse the welfare state, seem to favour a stronger welfare state than civic individuals who pay their taxes and do not abuse the welfare state (Algan et al., 2016), we find no significant relationship between individual civic behaviour and the support for the welfare state. Also, Algan et al.'s (2016) twin peak relationship between corruption and the size of the welfare state found in European OECD countries is not present in our sample with LAPOP data. ${ }^{5}$

We use a theoretical model to guide our empirical analysis. The choice of the model is guided by the nature of our empirical data. Our data set offers two different variables to capture corruption perceptions: people's impression whether the current administration combats corruption, and people's impression whether corruption among public officials is very common based on their own experience or on their information. These questions explicitly invoke public officials. We therefore use a theoretical model where corruption is captured by bribery. Since our data does not provide measures of people's rent-seeking abilities we abstract from corruption as rent-seeking for-tax revenue (Alesina and Angeletos, 2005; Dong and Togler, 2011). Moreover, our empirical variable for the support for redistribution, ${ }^{6}$ which asks to which extent the government should implement strong policies to reduce income inequality between the poor and the rich, ${ }^{7}$ suggests that the underlying government's policies may actually be effective, which is another reason not to model corruption as rent-seeking over government revenue in our context.

The two channels we include in our model are inequality and political trust, as they are variables measured in our data. To capture these channels we derive people's demand for redistribution by introducing redistributive taxation into a modified version of Foellmi and Oechslin's (2007) general equilibrium model of non-collusive corruption with capital market imperfections. Agents have heterogeneous initial assets which either serve to become a lender on the capital market or as collateral for the initial investment to become an entrepreneur which requires a license. Potential entrepreneurs might be asked for a bribe to get the license. We model corruption perceptions by the probability that a corrupt bureaucrat goes unpunished and study how corruption perceptions influence the demand for redistribution. Redistributive taxation involves a deadweight loss which we model as increasing in the probability of impunity of corrupt officials for two reasons. Firstly, greater redistribution by a corrupt government may create further rent-seeking opportunities to those who are able to benefit from corruption and leaves a smaller part of the government budget for redistribution. Secondly, perceiving high levels of corruption affects people's trust in public officials' willingness or ability to redistribute in an effective and impartial way (Robinson, 2008; Kuziemko et al., 2015). Through this channel more corruption leads to a lower demand for redistribution.

If borrowing is limited due to capital market imperfections, the presence of corrupt and immune bureaucrats causes income/wealth inequality to increase because their bribe demands preclude poorer individuals from starting their own business and benefit very rich individuals by lowering the cost of capital. More corruption therefore leads to fewer entrepreneurs with higher net returns while the returns to the rest of the population that acts as lenders on the capital market falls. This change in wealth is likely to lead to an overall higher taste for redistribution.

Our model therefore leads to two opposing effects of the perception of corruption on the support for redistribution. The net impact cannot be signed without making stark assumptions on underlying model parameters and is ultimately an empirical question. Since

\footnotetext{
2 To the best of our knowledge this question has not been studied in this region before. The closest study to ours is Algan et al. (2016). While they are mainly interested in the link between trust and the welfare state, they also examine the correlation between corruption and the welfare state at the macro level and perceived civic behaviour of compatriots and the welfare state at the micro level. Their analysis is for some selected OECD countries only and includes none of the countries in our Latin American sample.

3 This can be partly explained by populism or neo-liberalism (Leon, 2014).

4 Gaviria (2008), Ardanaz (2009), Cramer and Kaufman (2011), Morgan and Kelly (2010) and Daude and Melguizo (2010), empirically address the determinants of attitudes towards inequality and demand for redistribution in Latin America, but do not study the consequences of perceived corruption.

5 All this evidence is available upon request.

6 We also do not consider the ease of cheating by the recipients of transfers which influences individual preferences towards which groups redistribution should be targeted (Borisova et al., 2018).

7 This question is not about a de facto regressive tax system, hence we do not model bribery as a means of lowering the effective tax rate as in Dusha (2015).
} 
beliefs about corruption not only shape public policies, but are also influenced by policies and the institutional environment, we address this empirical question with a simultaneous equation model using individual bribery victimization as exclusion restriction.

Our empirical results suggest that perceived corruption enhances support for redistributive policies. That is, the channel due to reduced relative wealth levels of below-average-wealth individuals is positive in Latin America and seems to outweigh the effect of undermined trust in government and political institutions brought about by increased corruption. This conclusion is robust to different modelling options and various measures of corruption perceptions and of support for redistribution.

We do find evidence for the positive and the negative channel suggested in our theory. As for the positive channel we find evidence of a positive relationship between corruption perceptions and inequality, which supports the direct relationship between corruption and inequality derived in our model, i.e. the losers of a reduction in corruption are the rich, while the winners are likely to be the poorer, thus reducing inequality. Moreover, the data suggest that there is less credit in environments that are perceived as more corrupt, which gives force to the model's prediction that bribery creates more inequality by reducing collateral for potential entrepreneurs. As for the negative channel, we find evidence that corruption erodes political trust which justifies our model assumption that the deadweight loss of taxation increases with corruption perceptions. The negative channel from increased corruption perceptions to less demand for redistribution is indeed present in our data although it is weaker than the positive channel. Consequently, when controlling directly for political trust in our regressions the overall positive marginal effect of perceived corruption on support for redistribution increases.

We contribute to the literature in four ways. First, we provide new empirical evidence to the discussion of determinants of support for redistribution, emphasizing the relevance of the perceived quality of the institutional framework in general, and perceptions of corruption and trust in government institutions in particular. Second, we address the potential endogeneity of perceptions of corruption using an original instrument, namely data on corruption victimization as exclusion restriction. ${ }^{8}$ Third, we present novel empirical evidence for Latin America, a region where examining the link between corruption and support for redistributive policies is especially pertinent, as it displays high levels of inequality, widespread corruption, and low levels of redistribution. Finally, we make a small theoretical contribution by introducing redistributive taxation and political trust into Foellmi and Oechslin (2007) to guide our empirical analysis.

Due to the limited nature of our data we ignore two theoretically known channels from corruption perceptions to the demand of redistribution. We already mentioned rent-seeking. Alesina and Angeletos (2005) prove in a dynamic model that when people are heterogeneous in their rent-seeking abilities talented rent-seekers will be in favour of more redistribution but also the poor, since the gains from corruption as rent-seeking are unequally distributed in the population leading to more inequality. Since our data does not provide measures of people's rent-seeking abilities we abstract from modelling the rent-seeking motive explicitly and only mention rent-seeking as a factor underlying the deadweight loss of redistributive taxation. If rent-seeking ability is connected with people's wealth then our empirical results suggest that rent-seeking does not play a major role in our data, as support for redistribution declines with wealth levels in our regressions. Another channel ignored by our model are fairness concerns (Alesina and Angeletos, 2005). Individuals may deem inequality brought about by connections and corruption as less desirable than inequality resulting from effort. If this is the view of those who see corruption as a widespread problem, they will be more prone to consider inequality as a matter of social injustice and thus, demand more government intervention. The study by Cramer and Kaufman (2011) suggests that this channel might have some force: using public opinion data from Latinobarometro surveys conducted in 1997, 2001, and 2002, Cramer and Kaufman (2011) show that those who believe that corruption has increased in recent years are six per cent more likely to judge their country's distribution as very unfair.

The remainder of the paper is organized as follows. In Section 2 we present our modified version of Foellmi and Oechslin (2007)'s model of non-collusive corruption and outline the results that are important for the empirical part; we show full details of the model and the derivation of the results in the online appendix. The data for our empirical analysis is described in Section 3. Section 4 explains the empirical strategy. Results are presented in Section 5. Section 6 is dedicated to robustness checks. The last section concludes.

\section{A model of non-collusive corruption and preferences for redistribution}

In this section we will present the main ingredients of our model and outline the results which are important for our empirical part. The full model and the derivation of the results can be found in the online appendix. Our model is based on a slightly modified version of Foellmi and Oechslin (2007). We enrich their model by adding taxation and a deadweight cost of redistributive policies that increases with corruption perceptions. Our aim is to study how corruption perceptions, modelled by the probability of impunity of corrupt officials, affect preferences for redistribution captured by people's optimal tax rates.

We first explain the ingredients taken from Foellmi and Oechslin (2007). A closed economy is populated by continuous individuals of mass 1 who maximize their ex post wealth and are heterogeneous in their initial wealth levels, distributed according to the continuous distribution function $G(w)$. All agents can get a license from a bureaucrat to get access to a constant return technology that yields a return of $R$ to each capital unit invested but requires a minimum investment of $k \geq \kappa$ capital units. If they do not use their capital for production they can invest it as lenders in a competitive but imperfect economy-wide capital market at interest rate

8 Di Tella and MacCulloch (2006, 2009) study the effect of corruption on market regulation and defend the exogeneity of corruption perceptions using anger as a proxy to perceived corruption. 
$\rho .^{9}$ Credit obligations are imperfectly enforced. A defaulting borrower loses a fraction $\lambda \in[0,1]$ of the revenue he receives from his physical investment in the constant return technology. We assume that $\lambda R<\rho \leq R$.

There is a unit mass of bureaucrats without initial wealth. Each agent is matched to one and only one bureaucrat who offers the license to the agent in exchange for a bribe $b \geq 0$. Bureaucrats do not observe the assets of potential entrepreneurs and therefore set the same bribe for everybody. Bribe payments are invested in the capital market. Any bribe demand is detected with probability $1-\pi$ and results in a punishment $\mu(b)$ which is strictly increasing in the size of the bribe demanded, $\mu^{\prime}(b)>0$ and $\mu^{\prime \prime}(b)>0 .{ }^{10}$ Each bureaucrat sets the optimal bribe demand to maximize expected bribe payments minus expected punishment costs. ${ }^{11}$

Bribes will only be paid by those agents who actually become an entrepreneur and hence the bribe demands determines the minimum wealth necessary to be able to become an entrepreneur $w^{\min }(\kappa)$. These potential entrepreneurs will indeed become an entrepreneur if it is the most profitable option, i.e. their ex post tax wealth level as an entrepreneur is at least as high as their ex post tax wealth level as a lender.

Now we introduce our contribution to Foellmi and Oechslin (2007) which is to add taxation for redistributive purposes. Both entrepreneurs and lenders are taxed for their investments. The tax rate is $\tau$, taxation involves a deadweight loss, and the remaining money collected is equally distributed among agents via a per agent transfer $T$. The deadweight loss is an increasing function in the probability of impunity of public officials $\pi$. This captures the idea that the less likely it is that corrupt officials are apprehended the more of the government's budget is deviated for their private gains.

The way taxation is introduced does not affect agent's decision whether to become an entrepreneur or a lender, ${ }^{12}$ so as in Foellmi and Oechslin (2007) equilibrium interest rates and equilibrium bribe demands are unique, which allows us to determine each agent's unique preferred optimal tax rate. Importantly, only agents with a pre-tax wealth lower than the mean pre-tax wealth are in favour of redistribution and the lower the personal pre-tax wealth the bigger the demand for redistribution.

How does a change in corruption perceptions $\pi$ affect the optimal tax rate? There are two forces at play. On the one hand, an increase in the probability of impunity of a corrupt official increases the deadweight loss of taxation and hence reduces the demand for redistribution. This implies a negative trust channel from corruption to taste for redistribution: more corruption reduces preferences for redistribution. On the other hand, more impunity of corrupt officials affects both mean and personal pre-tax wealth levels. A higher corruption impunity leads to a higher bribe demand, a lower interest rate in the capital market and less entrepreneurs, ${ }^{13}$ making the poor poorer and the rich richer. Since only the poor want a positive tax rate and are made poorer by more corruption, this wealth/inequality channel from corruption to taste for redistribution is likely to be positive. Whether the positive or negative effect of corruption perceptions on demand for redistribution dominates is an empirical issue. We will now examine this issue for Latin America and seek to disentangle the trust effect and the wealth effect.

\section{Data}

To analyse empirically the relationship between perceptions of corruption and public support for redistribution, we use data for 18 countries $^{14}$ from the 2008, 2010 and 2012 rounds of the AmericasBarometer, a survey carried out by the Latin American Public Opinion Project (LAPOP), supported by the United States Agency for International Development, the United Nations Development Program, the Inter-American Development Bank, and Vanderbilt University. In 2004, LAPOP established the AmericasBarometer as face-to-face regularly conducted surveys of democratic values and citizens' behaviours, with a principal focus on Latin American democracies.

AmericasBarometer surveys use a common design for the construction of a multi-staged, stratified probabilistic sample of approximately 1500 individuals in each country per year, and stratified by major regions of the country and by urban and rural areas within municipalities. For the sample of 18 countries used in this paper, the pooled cross-section database counts 90,861 observations of individuals over 18 years of age. ${ }^{15}$ Due to the definition of some variables, the presence of missing values in some explanatory variables, and the definition of the exclusion restriction, ${ }^{16}$ the sample used in our baseline model is reduced to 71,102 observations, which accounts for 78 per cent of the initial sample.

Across countries, sample sizes range from 990 in Paraguay in 2012, to 2804 in Ecuador in 2010. For that reason, following LAPOP methodological guidelines, we reweighed the sample so that each country/year sample accounts for 1500 observations. This

\footnotetext{
9 In Foellmi and Oechslin (2007) agents have also access to a backyard technology yielding a return of $r<R$. This ensures a minimum return on capital of

10 The reader familiar with Foellmi and Oechslin (2007) should be aware that we define $\pi$ as the probability of impunity while they use the same notation for the probability of punishment. We make this change since the probability of impunity in our model is a proxy for perceived corruption.

11 The assumption that all bureaucrats are identical and all are corrupt simplifies the model considerably. It implies that the probability of punishment is identical to the extent to which the government fights corruption in our model and hence the probability of impunity captures the extent of perceived corruption in our model. The variable of interest in our baseline regression model is the individuals' perception of the extent to which government fights corruption (see Section 5). We obtain robust results when we used individuals' direct reports on perceived corruption as variable of interest (see Section 6.1).

12 Lemma 1 of online Appendix.

13 See online appendix for details and an illustrative figure.

14 Mexico, Guatemala, El Salvador, Honduras, Nicaragua, Costa Rica, Panama, Colombia, Ecuador, Bolivia, Peru, Paraguay, Chile, Uruguay, Brazil, Venezuela, Argentina and Dominican Republic.

1529,934 observations in 2008, 31,671 in 2010 and 29,256 in 2012.

16 "Doesn't know" answers and non-responses are coded as missing values.
} 
way, every country has the same impact on the overall sample as any other country. ${ }^{17}$ We prefer not to reweigh by population size, because in this case Brazilians and Mexicans would explain most of the variance of preferences in the region. Sample details can be found in Table A1 in the Online Appendix.

\section{Support for redistribution}

Questions that ask explicitly for the respondent's support to the role of government in reducing income inequality are considered an adequate measure for the preferences for political redistribution in the empirical literature (Corneo and Grüner, 2002; Alesina and Giuliano, 2011). In this spirit, we use the following question from the AmericasBarometer ${ }^{18}$ : "The government should implement strong policies to reduce income inequality between the rich and the poor. To what extent do you agree or disagree with this statement ?" Possible responses range from 1 to 7 , where ' 1 ' means "strongly disagree" and ' 7 ' means "strongly agree", so higher values indicate more support for redistribution. Average responses do not vary much across countries, but as Fig. 1 shows, a greater variance is observed in the percentage of people strongly in favour of redistribution. Strong support for reducing inequality ranges from 31 per cent in Venezuela and Bolivia to 64 per cent in Paraguay.

However, the distribution of the level of agreement with the statement within each country is clearly negatively skewed as most of the respondents express the highest levels of agreement - see Fig. 2. Therefore, and for convenience in the interpretation of results, we focus our analysis on individuals expressing strong agreement with redistribution. The dependent variable is thus built as a binary variable taking value 1 if the individual reports strong agreement with redistribution (i.e. her response is 7), and 0 otherwise. It is important to note that our results are not robust to defining support for redistribution in a wider manner to include less strong responses (e.g. 6 or below) in the category 1 of the binary variable.

\section{Perception of corruption}

In line with our model, we measure perception of corruption with a variable that captures the probability of impunity of public officials, $\pi$, from individuals' answer to the question: To what extent would you say the current administration combats government corruption? Since we want a measure of impunity, we reverse the seven values allowed in the answer, where ' 1 ' originally means "not at all" and '7' means "a lot", and collapse the information into a dummy variable that equals one if the individual reports that the fight against corruption is weak, corresponding to values 1,2 or 3, and zero otherwise. On average, 19 per cent of respondents report the administration not to fight corruption at all while only over 7 per cent believe that the administration combats corruption with maximum intensity (i.e. 7 in the original scale). Our dummy variable indicates that about half the individuals report impunity to be low while the other half hold impunity to be high. The country with the lowest percentage of people holding the believe that impunity is high is Uruguay (28 per cent), followed by Chile (32), while about 70 per cent report impunity to be high in Argentina and Paraguay - see Table 1 and Fig. 1.

Table 1

Perception of Corruption Impunity.

\begin{tabular}{lllllllll}
\hline & 1 & 2 & 3 & 4 & 5 & 6 & 7 & Total \\
\hline Mexico & 7.3 & 9.1 & 17.6 & 17.8 & 16.5 & 13.6 & 17.9 & 100 \\
Guatemala & 4.5 & 8.0 & 15.0 & 10.4 & 20.8 & 14.4 & 16.7 & 100 \\
El Salvador & 9.6 & 14.1 & 17.8 & 16.4 & 13.4 & 10.3 & 18.4 & 100 \\
Honduras & 2.5 & 5.4 & 15.3 & 22.6 & 21.9 & 9.0 & 23.3 & 100 \\
Nicaragua & 15.4 & 9.8 & 12.4 & 14.2 & 14.5 & 9.3 & 24.4 & 100 \\
Costa Rica & 7.6 & 7.8 & 16.1 & 18.6 & 17.0 & 10.1 & 22.9 & 100 \\
Panama & 4.0 & 7.6 & 18.7 & 21.9 & 16.6 & 10.0 & 21.2 & 100 \\
Colombia & 9.6 & 15.4 & 19.3 & 17.9 & 16.3 & 10.5 & 11.0 & 100 \\
Ecuador & 9.4 & 15.2 & 10.0 & 19.0 & 16.0 & 9.7 & 10.8 & 100 \\
Bolivia & 7.6 & 12.1 & 19.2 & 22.1 & 17.7 & 11.0 & 10.3 & 100 \\
Peru & 1.6 & 4.6 & 11.0 & 20.7 & 22.6 & 20.1 & 29.5 & 100 \\
Paraguay & 3.0 & 4.7 & 10.2 & 11.7 & 16.0 & 18.5 & 35.7 & 100 \\
Chile & 9.4 & 14.8 & 22.9 & 20.9 & 13.9 & 8.0 & 10.1 & 100 \\
Uruguay & 16.4 & 16.7 & 21.2 & 17.2 & 11.1 & 6.7 & 10.6 & 100 \\
Brazil & 7.0 & 8.0 & 14.2 & 16.2 & 17.4 & 13.7 & 23.6 & 100 \\
Venezuela & 7.6 & 8.5 & 13.5 & 14.3 & 12.3 & 14.8 & 29.1 & 100 \\
Argentina & 2.2 & 4.1 & 10.4 & 14.8 & 18.1 & 18.4 & 32.1 & 100 \\
Dominican Republic & 9.2 & 10.2 & 14.5 & 14.4 & 13.1 & 12.9 & 25.8 & 100 \\
\hline Total & 7.6 & 10.2 & 16.5 & 18.2 & 16.4 & 12.0 & 19.1 & 100 \\
\hline
\end{tabular}

Notes: Value ' 1 ' means lowest impunity and ' 7 ' means maximum impunity. This variable obtains by reversing the answers to the question: To what extent would you say the current administration combats government corruption?.

To check the robustness of our results we also use a different measure of perception of corruption; a dummy variable that equals one if respondents answer "very common" to the following question: "Taking into account your own experience or what you have heard, corruption among public officials is very common, common, uncommon, or very uncommon?". On average, 44 per cent of respondents report corruption among public officials to be a very common problem in their country, 36 per cent believe it is common, nearly 16

\footnotetext{
17 For more details about survey design and weighting scheme see: http://www.vanderbilt.edu/lapop/survey-designs.php

18 In the Spanish-language version of the questionnaire, the word "el estado" (the State) is used since the term "el gobierno" (the government) refers to the incumbent administration rather than the state apparatus: "El Estado debe implementar políticas firmes para reducir la desigualdad de ingresos entre ricos y pobres".
} 


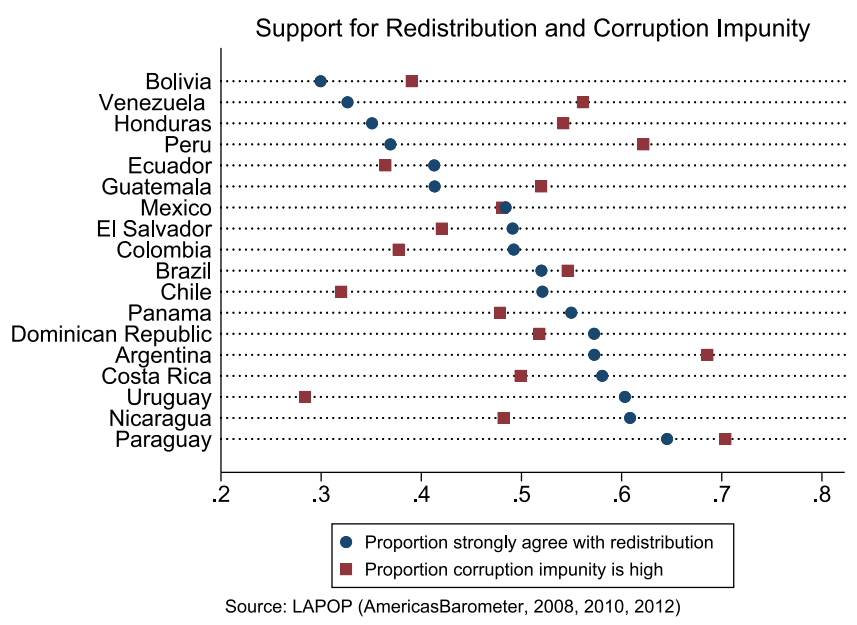

Fig. 1. Support for Redistribution and Corruption Impunity.

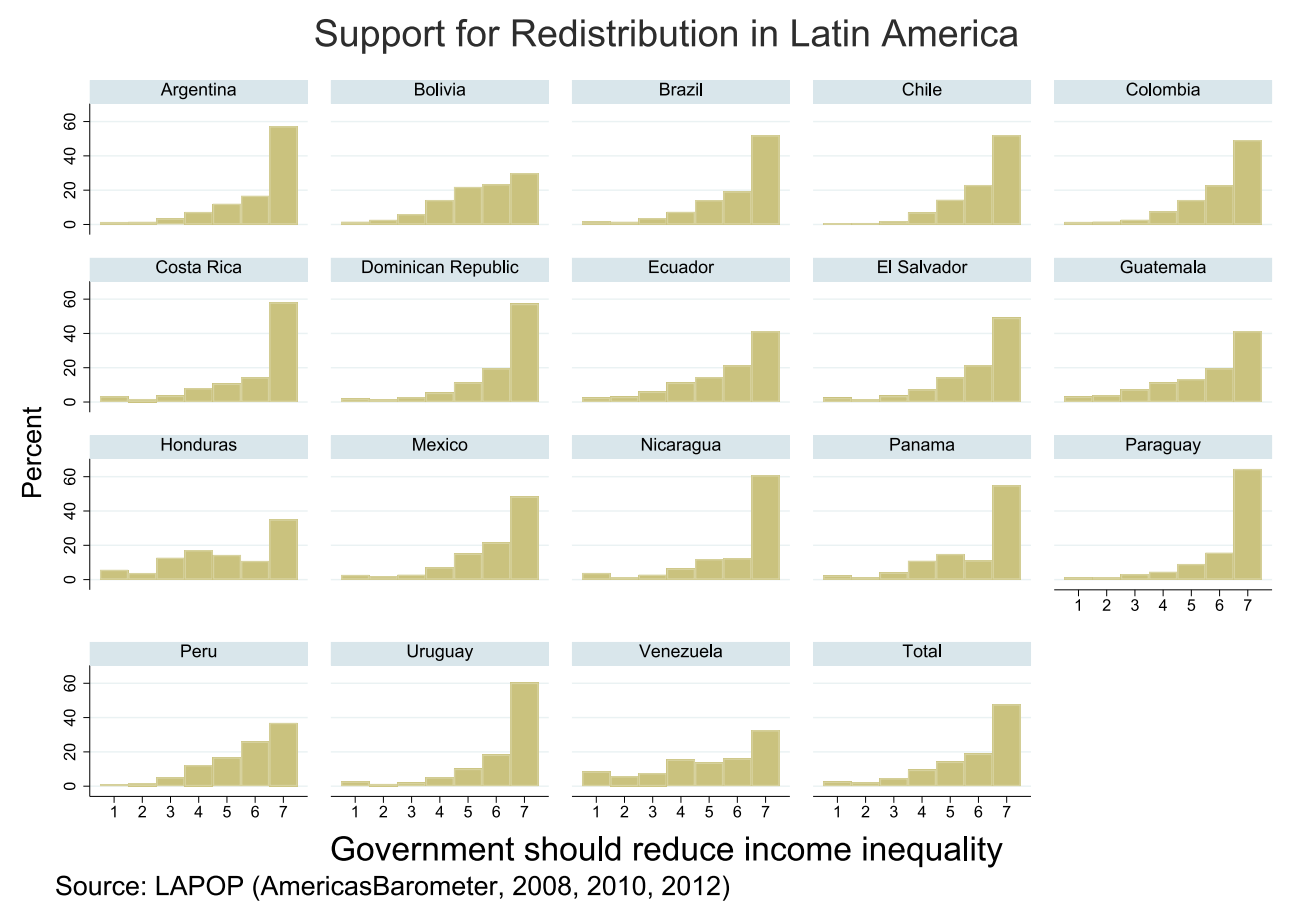

Fig. 2. Support for Redistribution by Country.

per cent regard it as uncommon, and only 4 per cent think corruption is very uncommon. The country with the lowest percentage of respondents holding the belief that corruption is a very common problem is Uruguay (23 per cent), followed by Chile (28), whilst more than 54 per cent hold this perception in the Dominican Republic and Argentina - see Table A2 and Figure A2, both in the Online Appendix. The association between the two variables we employ to proxy corruption perceptions is rather low (Cramér's $\mathrm{V}$ is 0.12).

Observe that the two questions we use to measure corruption perceptions make no sharp distinction between petty and grand corruption and allow people to base their answer on personal as well as general information. ${ }^{19}$ Notice that neither of these two variables need reflect the true level of corruption in a country and might differ from other measures of corruption. As Fig. 3 shows, there is only a moderate correlation between the percentage of people regarding corruption impunity as high and the Control of

\footnotetext{
19 We believe that this vagueness is a virtue rather than a vice for the purpose of our study since we are interested in people's perceptions about corruption in general not about a particular type of corruption and this perceptions should be based on all types of available information, not only on personal experience.
} 


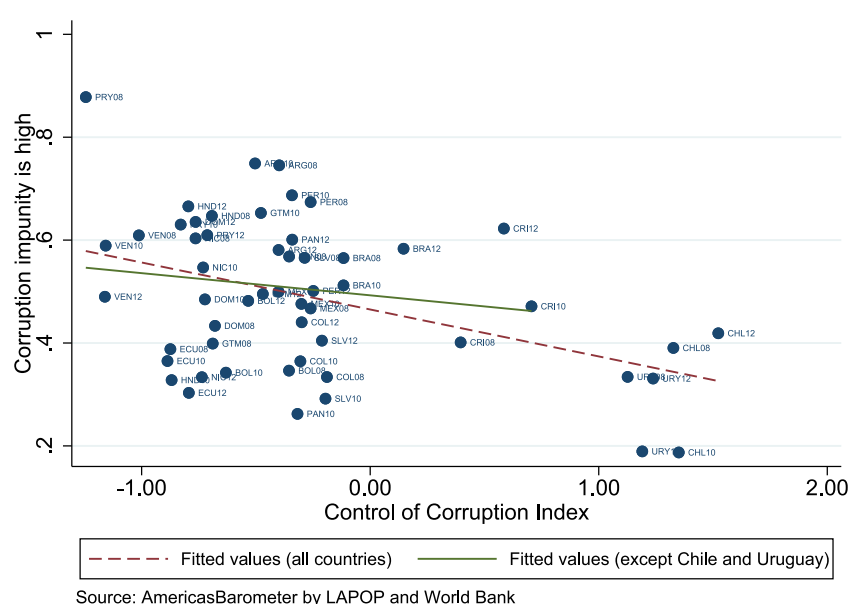

Source: AmericasBarometer by LAPOP and World Bank

Fig. 3. Correlation between WB CCI and Corruption Impunity from AmericasBarometer.

Corruption Index by the World Bank. ${ }^{20}$ Compared to expert perceptions about corruption, the perceptions of the general public are less based on personal information but are more related to the intensity of media coverage of important cases of corruption. We therefore control for exposition of political news in our regressions.

This possible potential lack of "accuracy" of perceptions of corruption regarding 'true' levels of corruption is not a weakness of our study. It is worth noticing, that there is no reliable and homogeneous way to measure the 'true' level of corruption in a country, so it is impossible to know to what extent individual perceptions differ from reality. Moreover and more importantly, people's preferences (and presumably their choices) depend on their beliefs, regardless of whether individuals' judgements of reality are accurate or not.

\section{Control variables}

Other individual socio-economic characteristics that previous studies have found relevant to understand differences in attitudes towards redistribution are used as controls (Alesina and Giuliano, 2011). We include gender, age, ethnic identification, religion, having children, years of education, labour status, city size, whether the respondent is exposed to political news on a daily basis, and the level of wealth - see Table A3 in the Online Appendix for the definition of the variables.

In the LAPOP survey data differences in income and wealth are captured by assets ownership. We built a linear wealth index by country and year using principal-components analysis to derive weights. ${ }^{21}$ This method provides a simple technique for creating a long-run household wealth proxy in the absence of either income or expenditure reliable data. ${ }^{22}$ Table A5 in the Online Appendix shows variations by quintile of the wealth index across income deciles in the 2008 and 2010 waves. In line with other studies (Filmer and Pritchett, 2001; Gasparini et al., 2008), we find a correlation of 0.5 between the decile of self-reported income and the wealth index. ${ }^{23}$ Besides income measurement errors, ${ }^{24}$ this moderate correlation is due to the fact that asset-based measures reflect the long term economic status of individuals or households which might not take short term fluctuations of income into account.

We also control for factors that have been found to correlate with our dependent variable: economic volatility, non civic behaviour, trustworthiness, and being a victim of crime. In the presence of economic volatility individuals may be more supportive of redistribution as insurance against future income loss (Mares, 2005; Rehm, 2011). We expect support for redistribution to be

20 The correlation becomes even less strong when the cases of Chile and Uruguay, which show a low level of corruption according to both individuals' perceptions and experts' opinions, are excluded from the sample. Figure A3 in the Online Appendix also shows that the correlation between the percentage of people regarding corruption as a very common problem and the Control of Corruption Index by the World Bank is moderate. Finally, the correlation is of a similar magnitude with similar indices, such as the Corruption Perceptions Index (CPI) by International Transparency Organization, most often used measure of perception of corruption and relies mainly on experts' perceptions.

21 We follow Filmer and Pritchett (2001). As a robustness check we compare the quantiles obtained from this method with those that result from polychoric principal components (Kolenikov and Angeles, 2009), and find that both methods yield very similar results - 98 per cent of the quantiles are the same. Table A4 in the Online Appendix lists the variables included.

22 The LAPOP survey also offers data on self-reported income range for the entire household. We decided not to use this measure because there is a lot of non-response in this variable and the scale used in the 2012 wave is not comparable with the scale used in previous waves.

23 Filmer and Pritchett (2001), for instance, find correlation coefficients between the asset index and expenditures between 0.43 and 0.64 for developing countries. Gasparini et al. (2008), using data for Latin America and the Caribbean from the Gallup World Poll of 2006, construct an indicator of deprivation based on a multidimensional non-monetary index by taking into account information on durable goods and access to some facilities (water, electricity, telephone, etc.), and find the correlation between this index and self-reported household income to be 0.46 .

24 Measurement error arises, for instance, from large non-response rates, from income being usually reported in brackets (leading to just a rough measure of income), and because the questionnaire may be answered by a household member, who is not necessarily the one who knows her household income better. 
larger amongst individuals whose economic situation is not the same as it was 12 months earlier (i.e. either worse or better). ${ }^{25}$ Civic behaviour is advocated to have a direct impact on individual preferences for redistribution (Algan et al., 2016). Our variable of non-civic behaviour indicates whether the respondent believes that paying a bribe is justified. Trustworthiness of citizens is also argued and found to be positively correlated with support for the welfare state (Rothstein and Uslaner, 2005; Bjørnskov and Svendsen, 2013; Daniele and Geys, 2015). ${ }^{26}$ Crime victimization is argued to determine demand for redistribution in two ways. First, to have social protection through the state as a way of coping with the economic, health, and emotional costs of crime (Altamirano et al., 2020) and, second, to reduce crime through welfare policies (Alesina and Giuliano, 2011; Rueda and Stegmueller, 2016).

Time and aggregate factors are captured by time and region fixed effects, and their interaction terms. Time-specific shocks common to all regions and countries are controlled for by time fixed effects. Region-specific time-invariant heterogeneity, such as institutional or cultural features (e.g. state capacity), ${ }^{27}$ inequality, poverty, social expenditure, or economic growth is captured by region fixed effects. Interaction terms between year and region are also included to make sure that the effect of individual corruption perceptions on preferences for redistribution is not driven by time-region specific effects. Summary statistics of all the variables is available in Table A6 in the Online Appendix.

\section{Empirical strategy}

We first estimate a simple reduced form of individual preferences for redistribution, which are modelled by a latent variable $y_{i}^{*}$

$$
y_{i}^{*}=c_{i} \gamma+x_{i} \beta+\varepsilon_{i}
$$

where $y_{i}^{*}$ stands for the individual support for redistribution and $c_{i}$ captures the individual's belief of how widespread corruption impunity is; $x_{i}$ is a vector that includes the control variables mentioned above (such as age, gender, level of wealth, occupation, etc.) as well as the time, region, and time-region fixed effects, which affect directly the individual likelihood of favouring redistribution ${ }^{28}$; and $\varepsilon_{i}$ is the error term assumed to be independent of regressors $x_{i}$ and $c_{i}$. The vectors $\beta$ and $\gamma$ are parameters to be estimated. The parameter $\gamma$ expresses the correlation between the perceived level of corruption and the probability of favouring redistributive policy.

The variable $y_{i}^{*}$ is not observed. Instead we observe a variable $y_{i}$ that equals 1 if the individual strongly favours redistribution, and 0 otherwise $\left(y_{i}=1\right.$ if $\left.y_{i}^{*}>0\right)$. Assuming a normal distributed error term, $y_{i}$ is estimated using a probit regression model.

Since it is possible that the same unobserved factors influencing the propensity to advocate greater redistribution are generating endogenous variation in the level of perceived corruption impunity, ${ }^{29}$ the causality of the conclusions on the sign of $\gamma$ depends on a proper treatment of the potential endogeneity problem.

To address endogeneity, we use a simultaneous bivariate model which implies the estimation of the joint probability distribution of two or more variables in a simultaneous specification (Wooldridge, 2010) ${ }^{30}$ Specifically, we use a recursive bivariate probit model (Greene and Hensher, 2009) where the disturbances of the two equations are assumed to be correlated. Thus, this model allows us to estimate the effect of interest while accounting for unobserved confounders. The general specification is as follows:

$$
\begin{array}{llll}
y_{i}^{*}=x_{1 i} \beta_{1}+c_{i} \gamma+\varepsilon_{1 i}, & y_{i}=1 & \text { if } y_{i}^{*}>0, \quad 0 \text { otherwise } \\
c_{i}^{*}=x_{2 i} \beta_{2}+\varepsilon_{2 i}, & c_{i}=1 \quad \text { if } c_{i}^{*}>0, \quad 0 \text { otherwise }
\end{array}
$$

where $c_{i}^{*}$ and $y_{i}^{*}$ are continuous latent variables which determine the observed binary outcomes $y_{i}$, $c_{i}$, which equal 1 if the corresponding latent variable is greater than a given threshold, and zero otherwise. $x_{1 i}$ and $x_{2 i}$ are vector of variables explaining attitudes towards redistribution and perceptions of corruption respectively, while $\beta_{1}$ and $\beta_{2}$ are vectors of unknown parameters. The parameter $\gamma$ is an unknown scalar, and it is again the main parameter of interest, which can be understood as the average treatment effect of perceiving a high level of corruption impunity. Finally, $\varepsilon_{1 i}$ and $\varepsilon_{2 i}$ are error terms that are independent of $x_{1 i}$ and $x_{2 i}$ but not necessarily independent of each other, i.e. $E\left[x_{1 i} \varepsilon_{1 i}\right]=0$ and $E\left[x_{2 i} \varepsilon_{2 i}\right]=0 . \varepsilon_{1 i}$ and $\varepsilon_{2 i}$ are assumed to be distributed as bivariate

\footnotetext{
25 As a robustness check we use a more refined measure of volatility based on both past and expected change in own economic situation, that LAPOP included in 2010 only. The more refined measure of volatility takes value 0 if individuals report expecting the same economic situation in 12 months time as they had in the 12 months previous to the interview and takes value 1 if their expected economic situation differs from the one they report for the previous 12 months.

26 Algan et al. (2016) posit that this relationship is non-linear, partly because people who believe to be surrounded by more trustworthy citizens have stronger support for the welfare state. This predictions do not hold for our sample of Latin American countries - evidence available upon request. Social capital, a concept much related to trustworthiness, also leads to an increased demand for redistribution (Yamamura, 2012).

27 State capacity and the ability of the state to police free-riding is critical for individuals to support the welfare state (Mares and Carnes, 2009). Weak state capacity and institutions reduce the support for redistribution amongst those who have to actually pay for it.

28 For simplicity, we omit here the time, and region subscripts.

29 For instance, perceptions of corruption depend on how a society understands the rules and what constitutes a deviation (Melgar et al., 2010), which in turn depends on unobserved personal characteristics (values and moral views, aversion to inequality, for instance) that may also affect views on inequality. In a related work, Di Tella and MacCulloch (2006, 2009) acknowledge that a positive effect of perception of corruption on demand for regulation, for instance, might simply identify a fixed trait of left-wing citizens, namely a greater tendency to regard corruption as a pervasive phenomenon, or less tolerance with corruption than right-wingers.

30 In linear models with an endogenous right-hand side variable instrumental variables techniques are a common solution. However, in non-linear models this procedure is no longer directly applicable because these sort of models are not invertible and there is no expression of the error term (Arellano, 2007). As in any latent variable model, in this setting $y^{*}$ is not observed, only $y_{i}$ is. The "residual" would have no meaning even if the true parameters were known. As a robustness check we provide OLS and IV estimates of the model (see Appendix A2).
} 
standard normal with correlation $\rho$, this is: $F\left(\varepsilon_{1 i}, \varepsilon_{2 i}\right)=\Phi_{2}\left(\varepsilon_{1 i}, \varepsilon_{2 i}, \rho\right)$, where $\Phi_{2}$ denotes the cumulative density function of the bivariate standard normal distribution.

The recursive bivariate probit model introduces two sources of dependence between $c_{i}$ and $y_{i}$, related to the parameters $\gamma$ and $\rho$, respectively. While the joint model simplifies to two univariate probit equations under independence of the structural errors ( $\rho=0$ ), this does not mean that $c_{i}$ and $y_{i}$ are independent because the first probit equation of the recursive base model gives the probability of $y_{i}$ conditional on $c_{i}$. Therefore, full independence of $c_{i}$ and $y_{i}$ would require $\rho=0$ and $\gamma=0$ (Winkelmann, 2011: 4).

In this setting, the exogeneity condition is stated in terms of the correlation coefficient; the variable $c_{i}$ is endogenous when $\operatorname{corr}\left(\varepsilon_{1 i}, \varepsilon_{2 i} \mid x_{1 i}, x_{2 i}\right)=\rho \neq 0$. On the contrary, when $\rho=0, y_{i}$ and $\varepsilon_{2 i}$ are uncorrelated and therefore $c_{i}$ is exogenous. Thus, the null hypothesis of interest is that $\rho=0$, that is, an exogeneity hypothesis. The usual parametric approaches to exogeneity testing, such as the likelihood ratio test and the 'z-test' based on the maximum likelihood estimator of $\rho$, are suitable for endogeneity testing in this kind of models (Monfardini and Radice, 2008). Whenever the exogeneity hypothesis cannot be rejected, the model can be simplified and estimated as two separate models for each outcome of interest.

\section{Identification strategy}

The parameters in the system of equations (2) are identified by imposing an exclusion restriction on vectors $x_{1}$ and $x_{2}$, i.e. at least one element of $x_{2}$ should not be present in $x_{1}$ to avoid that identification strongly relies on functional form and non-linearity (Han and Vytlacil, 2017; Li et al., 2019). One should find at least one variable that is believed to be correlated with $c_{i}$ but independent of $y_{i}$. This variable is included only in $x_{2}$ to obtain the consistent estimates of $\gamma, \beta_{1}$ and $\rho$.

Our exclusion restriction is individual bribery victimization, namely, whether the respondent reports having been asked for a bribe by a police officer or a government employee in the twelve months previous to the survey. ${ }^{31}$ We thus assume that victims of bribery are more likely to perceive higher corruption, but that the bribery episode does not directly shape their redistributive preferences. We control for individual characteristics that determine the likelihood of being victimized. Individuals who are wealthier, highly educated, and living in bigger cities are more likely to be asked for a bribe, as they are more likely to be in contact with public bureaucracy. On the other hand, women and older people are less likely to be victims of bribery.

Bribery episodes should not directly affect the support for redistribution, but only through perceptions of corruption. In so far as bribery incidents signal the inability of governments to control their bureaucrats, one such channel could be weak state capacity. There are ties between corruption and weak state capacity, on the one hand, and between weak state capacity and inability to prevent tax evasion, on the other (Acemoglu, 2005; Gehlbach, 2006). This potential tax evasion decreases support for social policy amongst the general populace due to concerns for free-riding (Ait Bihi Ouali, 2020). This could violate the exclusion restriction, as incidents of bribery could shape support for redistribution via this free-rider logic. However, in Latin America the direction of causality of this argument is likely to be reversed. Castañeda et al. (2020) contend that individuals in Latin America see the welfare state as a social contract from which one can opt out. Using a list experiment design, those who opt out are found more likely to evade taxes. So, contrary to the standard argument, individuals do not simply evade taxes when the expected benefits are low, but before evading taxes they first distance themselves from state-provided goods and opt for privately provided substitutes. This finding, which refers to Latin America, eliminates concerns about the possibility that incidents of bribery in our sample, our exclusion restriction, capture the alternative channel of weak state capacity. Furthermore, Castañeda et al. (2020) also find that individuals who perceive higher rates of corruption are not more willing to evade taxes. This suggests that any effect we may find on support for redistribution of exogenous variation of perceived corruption is not mediated by tax evasion motives.

According to the evidence provided by Castañeda et al. (2020), state capacity does not represent a threat to our identification strategy. The array of fixed effects (region, time, and interaction) capture both region- and time-specific features of weak institutional capacity as well as more idiosyncratic elements by means of the interaction effects. All these controls should build confidence that the exclusion restriction is met and state capacity is not an alternative channel.

Table 2 shows the distribution of bribery episodes by country and year. Overall, 10.4 per cent of respondents were asked for a bribe by a police officer, while 5.4 per cent were asked for a bribe by a government employee. In total, 12 per cent of the survey sample was victim of bribery. Countries with highest level of bribery are Bolivia, Mexico and Peru, with shares above 20 per cent, while countries at the other end are Chile (2.7), Uruguay (5.3) and Brazil (5.1).

\section{Empirical results}

We first present the results of the probit and bivariate probit models. Then we discuss the issue of endogeneity of perceived corruption. Section 5.3 checks whether higher corruption perceptions increase distrust in government institutions, which would be evidence for the negative channel from corruption perceptions to taste for redistribution in our model.

\footnotetext{
31 The wording of each question is: "Has a police officer ask you for a bribe during the past year?", "During the past year, did any government employee ask you for a bribe?" The latter question includes several specific situations: at the respondent's workplace, in the courts, in public health services, or at school.
} 
Table 2

Bribery victimization by year and country.

\begin{tabular}{lrrrr}
\hline & 2008 & 2010 & 2012 & Total \\
\hline Mexico & 20.8 & 27.6 & 21.5 & 23.3 \\
Guatemala & 12.5 & 16.0 & 19.3 & 15.9 \\
El Salvador & 8.5 & 7.7 & 6.7 & 7.7 \\
Honduras & 9.5 & 11.1 & 18.6 & 13.1 \\
Nicaragua & 11.3 & 8.8 & 5.9 & 8.7 \\
Costa Rica & 10.5 & 7.3 & 7.1 & 8.3 \\
Panama & 5.0 & 5.3 & 3.9 & 4.7 \\
Colombia & 6.5 & 7.9 & 11.4 & 8.6 \\
Ecuador & 16.0 & 13.4 & 18.5 & 16.0 \\
Bolivia & 23.6 & 22.5 & 23.6 & 23.3 \\
Peru & 20.5 & 22.2 & 18.8 & 20.5 \\
Paraguay & 14.8 & 17.1 & 15.6 & 15.8 \\
Chile & 2.4 & 2.9 & 2.9 & 2.7 \\
Uruguay & 4.9 & 5.5 & 4.8 & 5.1 \\
Brazil & 3.9 & 6.7 & 5.4 & 5.3 \\
Venezuela & 6.4 & 11.9 & 8.7 & 9.0 \\
Argentina & 18.8 & 14.9 & 11.5 & 15.1 \\
Dominican Republic & 11.2 & 12.7 & 17.1 & 13.7 \\
\hline Total & 11.5 & 12.3 & 12.3 & 12.0 \\
\hline
\end{tabular}

\subsection{Effect of perceived corruption impunity on support for redistribution}

Columns 1 and 3 in Table 3 present the estimated marginal effects of perceiving a high level of corruption impunity on the probability to strongly support redistributive policies from univariate and bivariate probit models respectively. The main result is that the effect of perceived corruption impunity is positive in both models, namely, those who believe corruption impunity to be high are more likely to support redistribution. The marginal effect in the univariate probit model is 4.6 percentage points, while in the bivariate model the effect is four and a half times larger. As we discussed above in Section 4, the larger effect in the bivariate model may be explained by the presence of unobserved individual variables, such as moral values or views, that correlate with corruption impunity perceptions and also, but with the opposite sign, with preferences for redistribution. As the bivariate model yields a larger estimate than the univariate model, the bias introduced by the omitted variables is negative. Thus the possible presence of endogeneity, which we thoroughly address in the next section, does not challenge our estimated positive effect.

Notice also that the difference in the marginal effect between the univariate and the bivariate models does not come from using a weak exclusion restriction. As we report in Section 5.2, our exclusion restriction shows a positive and very precisely estimated positive correlation with the endogenous variable, corruption impunity perceptions ( $z$-test of 7.2).

These results can be interpreted as the positive effect of perceived corruption dominating the potential negative effect of corruption related to distrust in government intervention and modelled as an increase in the deadweight loss of taxation. ${ }^{32}$

We cannot run a direct test on the positive channel, as the AmericasBarometer does not provide enough information to identifying the members of the population who expect that their position in the overall income distribution will be lower because of the opportunities that corruption forecloses to them. Notwithstanding this, we provide aggregate evidence in line with the model predictions. First, we find evidence of a positive relationship between corruption perceptions and inequality, ${ }^{33}$ which is consistent with the direct relationship between corruption and inequality derived in our model, i.e. the losers of a reduction in corruption are the rich, while the winners are likely to be the poorer, thus reducing inequality. Moreover, the data suggests that there is less credit in environments that are perceived as more corrupt, which gives force to the model's prediction that bribery creates more inequality by reducing collateral for potential entrepreneurs.

Moreover, our data also provides preliminary evidence for the channel proposed by our model as to why higher corruption impunity perceptions lead to more inequality, namely by reducing the collateral that some agents can use to guarantee the minimum capital they need to invest, which implies falling total demand for credit. We indeed find a negative correlation between Domestic Credit to the Private Sector and corruption impunity. ${ }^{34}$

\footnotetext{
32 Notice that the positive effect captured by corruption impunity is not likely to measure the possible effect of larger uncertainty that increased corruption perceptions may cause, as we directly control for economic volatility in the regressions. Consistent with previous work, the estimate of our volatility variable suggests a positive link between economic volatility and support for redistribution, i.e. individuals who report changes in their economic situation show stronger support for redistribution. This result also holds when we use our more refined measure of volatility, which is only available for one of the three years included in our sample.

33 We find a positive (11.3) and significant ( $t$-stat $=2.17$ ) OLS estimate of corruption perceptions on inequality (measured by the gini coefficient multiplied by 100) in a country level regression that also includes country/year GDP, and year and country fixed effects. The mechanism that derives from our model is of course but one possible mechanism explaining the direct relationship between corruption perceptions and inequality.

34 The data for Domestic Credit to the Private Sector (DCPS) is from the World bank. The correlation between DCPS and corruption impunity is -0.078 ( $p$-value $=0.0001$ ). The correlation between DCPS and corruption perceptions is -0.080 ( $p$-value $=0.0001$ ). Results do not change if we take into account year effects and run a probit regression of corruption impunity (or corruption perceptions) on DCPR and year dummies.
} 
Table 3

Support for Redistribution and Perception of Corruption Impunity.

\begin{tabular}{|c|c|c|c|c|c|c|c|c|c|}
\hline & \multicolumn{3}{|c|}{ Univariate Probit Model } & \multicolumn{6}{|c|}{$\begin{array}{l}\text { Bivariate Probit Model } \\
(\operatorname{Pr}[y=1, c=1])\end{array}$} \\
\hline & \multirow{2}{*}{\multicolumn{3}{|c|}{ (1) }} & \multicolumn{3}{|l|}{$(2)$} & \multicolumn{3}{|l|}{ (3) } \\
\hline & & & Redistribution & \multicolumn{3}{|c|}{ Corruption impunity } & \multicolumn{3}{|c|}{ Redistribution } \\
\hline & $d y / d x$ & & $(z)$ & $d y / d x$ & & $(z)$ & $d y / d x$ & & $(z)$ \\
\hline Corruption impunity & 0.046 & $* * *$ & $(5.44)$ & & & & 0.209 & *** & $(2.96)$ \\
\hline \multicolumn{10}{|c|}{ Economic situation w.r.t 12 months ago: Better (ref.) } \\
\hline Same & -0.028 & *** & $(-4.36)$ & 0.074 & **** & $(12.22)$ & -0.024 & **** & $(-4.20)$ \\
\hline Worse & -0.010 & & $(-1.43)$ & 0.163 & $* * *$ & $(15.63)$ & -0.007 & & $(-1.09)$ \\
\hline \multicolumn{10}{|c|}{ People in this community are generally: Untrustworthy (Ref.) } \\
\hline Somewhat trustworthy & -0.019 & $* *$ & $(-2.08)$ & -0.044 & **** & $(-5.78)$ & -0.018 & ** & $(-2.10)$ \\
\hline Not very trustworthy & -0.013 & & $(-1.29)$ & -0.063 & $* * *$ & $(-7.65)$ & -0.012 & & $(-1.33)$ \\
\hline Very trustworthy & 0.035 & **** & $(3.37)$ & -0.091 & $* * *$ & $(-11.14)$ & 0.032 & *** & $(3.15)$ \\
\hline Non-civic behaviour & -0.010 & & $(-1.38)$ & 0.028 & $* * *$ & $(4.32)$ & -0.009 & & $(-1.44)$ \\
\hline Victim of crime & 0.030 & **** & $(5.27)$ & 0.034 & $* * *$ & $(6.09)$ & 0.028 & $* * *$ & $(5.10)$ \\
\hline Female & -0.006 & & $(-1.38)$ & 0.005 & & $(1.07)$ & -0.005 & & $(-1.20)$ \\
\hline White or Mestizo & -0.013 & $*$ & $(-1.93)$ & -0.010 & & $(-1.45)$ & -0.012 & $* *$ & $(-1.97)$ \\
\hline Age & 0.000 & & $(0.95)$ & 0.000 & & $(1.08)$ & 0.000 & & $(1.03)$ \\
\hline Has children & 0.028 & $* * *$ & $(4.98)$ & -0.006 & & $(-1.09)$ & 0.026 & $* * *$ & $(4.89)$ \\
\hline Catholic & -0.026 & **** & $(-4.68)$ & -0.004 & $*$ & $(-1.85)$ & -0.024 & *** & $(4.60)$ \\
\hline \multicolumn{10}{|c|}{ Labour Status: Worker in private sector (ref.) } \\
\hline Inactive & 0.006 & & $(0.96)$ & -0.024 & $* * *$ & $(-4.19)$ & 0.005 & & $(0.94)$ \\
\hline Unemployed & 0.010 & & $(1.09)$ & -0.019 & $* *$ & $(-2.06)$ & 0.009 & & $(1.05)$ \\
\hline Worker in public sector & 0.027 & $* * *$ & $(2.91)$ & -0.070 & $* * *$ & $(-7.05)$ & 0.025 & $* * *$ & $(2.69)$ \\
\hline Employer or entrepreneur & -0.021 & & $(-1.14)$ & -0.016 & & $(-0.99)$ & -0.020 & & $(-1.19)$ \\
\hline Self-employed & 0.001 & & $(0.08)$ & -0.010 & $*$ & $(-1.69)$ & 0.000 & & $(0.05)$ \\
\hline News daily & 0.030 & $* * *$ & $(4.58)$ & -0.016 & $* * *$ & $(-2.83)$ & 0.028 & $* * *$ & $(4.27)$ \\
\hline \multicolumn{10}{|l|}{ Wealth index: Quintile 1 (ref.) } \\
\hline Quintile 2 & -0.008 & & $(-1.07)$ & 0.009 & & $(1.57)$ & -0.007 & & $(1.05)$ \\
\hline Quintile 3 & -0.013 & & $(-1.35)$ & 0.026 & $* * *$ & $(3.76)$ & -0.012 & & $(-1.33)$ \\
\hline Quintile 4 & -0.019 & $*$ & $(-1.78)$ & 0.031 & $* * *$ & (4.03) & -0.017 & * & $(-1.77)$ \\
\hline Quintile 5 & -0.055 & **** & $(-5.43)$ & 0.049 & $* * *$ & $(5.71)$ & -0.052 & $* * *$ & $(-5.59)$ \\
\hline Education (years) & -0.000 & & $(-0.06)$ & 0.004 & $* * *$ & $(4.46)$ & $-0-000$ & & $(-0.40)$ \\
\hline \multicolumn{10}{|c|}{ City size: Capital or big city (ref.) } \\
\hline Medium city & 0.023 & $* *$ & $(2.15)$ & -0.010 & & $(-1.09)$ & 0.021 & **** & $(2.10)$ \\
\hline Small city & -0.005 & & $(-0.47)$ & -0.033 & **** & $(-3.72)$ & -0.005 & & $(-0.50)$ \\
\hline Rural & 0.010 & & $(1.06)$ & -0.026 & $* * *$ & $(-3.75)$ & 0.009 & & $(0.98)$ \\
\hline Individual bribery & & & & 0.050 & $* * *$ & $(7.20)$ & & & \\
\hline \multicolumn{4}{|c|}{ Fisher's $z$ transformed correlation } & & & & -0.284 & *** & $(-2.14)$ \\
\hline Pseudo $R^{2}$ & \multicolumn{9}{|l|}{0.066} \\
\hline Observations & \multicolumn{3}{|l|}{71,102} & \multicolumn{6}{|l|}{71,102} \\
\hline Pseudo Log Likelihood & \multirow{2}{*}{\multicolumn{3}{|c|}{$-40,983.7$}} & \multicolumn{6}{|l|}{$-80,522.2$} \\
\hline Walt test of $\rho=0$ & & & & \multicolumn{3}{|l|}{$\chi^{2}(1)=4.57$} & & & \\
\hline
\end{tabular}

Notes: Average marginal effects of univariate and recursive bivariate probit models where each dependent variable equals 1 if the respondent strongly agrees with the statement "Government should implement strong policies to reduce income inequality". All regressions include fixed effects at region and year level, as well as region-year interaction terms. $z$-statistics in parenthesis. Standard errors are clustered at region level. *** significant at 1 per cent; ** significant at 5 per cent; * significant at 10 per cent.

Estimates from linear probability models (LPM) and instrumental variables reported in Appendix A2 yield the same results as uni- and bivariate probit models. The marginal effect of perceived corruption impunity on preferences for redistribution is positive, and it is larger when endogeneity is corrected. We also show that our instrument meets the standard conditions to be considered relevant and exogenous.

Note also that, as our model predicts, support for redistribution decreases with the wealth level. This decrease is statistically significant for the fourth and fifth wealth quintiles. ${ }^{35}$

\subsection{Is perceived corruption impunity endogenous?}

As explained in Section 4, exogeneity of corruption impunity perceptions requires independence of the two structural error terms. As Fisher's $z$ transformed correlation indicates at the bottom of Column 3 in Table 3, the sign of the estimated correlation of the two error terms, $\rho$, is negative, and statistically significant.

\footnotetext{
35 If wealth is linked to rent-seeking opportunities, this finding suggests that the rent-seeking motive for support for redistribution as suggested by Alesina and Angeletos (2005) does not play an important role in our data. This is not surprising, since rent-seeking diverts funds from redistribution to personal gains and the question for support for redistribution used in our data suggest that redistribution is effective.
} 
Table 4

Test of Exogeneity Based on Generalized Residuals.

\begin{tabular}{lll}
\hline & $\begin{array}{l}(2) \\
\text { Baseline } \\
\mathrm{b} /(\mathrm{z})\end{array}$ & $\begin{array}{l}(3) \\
\text { Generalized residuals } \\
\mathrm{b} /(\mathrm{z})\end{array}$ \\
\hline Corruption Impunity & $0.124^{* * *}$ & $0.663^{* * *}$ \\
& $(5.44)$ & $\begin{array}{l}(2.39) \\
\text { Generalized residuals }\end{array}$ \\
& & $-.330^{*}$ \\
\hline R-squared & 0.066 & 0.066 \\
Observations & 71,102 & 71,102 \\
Pseudo Log Likelihood & $-40,983.7$ & $-40,846.1$ \\
\hline
\end{tabular}

Notes: Results of the coefficient of generalized residuals in a probit model of support for redistribution. Models include the same set of controls as in Table 3. *** significant at 1 per cent; ** significant at 5 per cent; * significant at 10 per cent.

We use two different methods to test the hypothesis of exogeneity. The first one is a likelihood ratio test based on the idea that if $\rho$ equals zero, the log-likelihood for the bivariate probit will be equal to the sum of the log-likelihoods from the two univariate probit models. Since we use heteroscedasticity robust clustered standard errors, ${ }^{36}$ this becomes a Wald test. As displayed in the last row of Table 3 the statistic of this test is equal to 4.6, and it is distributed as a $\chi^{2}$ with one degree of freedom under the null hypothesis, with a $p$-value of 0.03 indicating that the hypothesis that errors in both equations are independent can be rejected at the conventional 5 per cent level.

The second test uses an extension of the Rivers and Vuong (1988) approach, which implies a two-stage method, namely, obtaining the generalized residuals from the first-stage probit of perceived corruption impunity on individual bribery victimization, other controls and the fixed effects, estimating a second-stage probit that includes such residuals as explanatory variable, and conducting a $t$-test on the estimate of the residuals. As usual, the null hypothesis is that corruption impunity perception is exogenous. ${ }^{37}$ As can be seen from Table 4, the residuals are significantly different from zero. The Wald test yields a $\chi^{2}$ statistic equal to 3.89 , with a $p$-value of 0.05. Again we can reject the hypothesis of exogeneity, at 6 per cent.

Table 3 shows that the exclusion restriction is significant at 1 per cent level to explain individual perception of corruption impunity; having been a victim of bribery increases the probability of perceiving corruption impunity by 5 percentage points. Not only is the $t$-test statistic (7.2) one of the highest statistics amongst the set of covariates, but also different tests in the context of instrumental variables estimation provide evidence about the validity of this exclusion restriction (see Appendix A2).

Given our main finding that perceived corruption impunity has a strong positive effect on the demand for redistribution, Appendix A3 examines what explains that some individuals perceive more corruption impunity than others.

\subsection{Perceptions of corruption impunity and (dis)trust in government institutions}

Our data suggests an overall strong positive effect of perceived corruption impunity on the probability of supporting redistribution. Our theoretical model points to two opposing forces. Can we find any evidence for the negative effect? The deadweight cost that underlies the negative channel captures the idea that the less corruption is detected, the more funds are drained from public policy. This deviation of government's budget from public purposes reduces individuals' trust in the government. To test the validity of this hypothesis we need to check whether perceived corruption impunity reduces trust in government and whether distrust in government indeed reduces people's support for redistribution. In order to do so we include an additional variable to our baseline model (2), measuring individual's level of trust in government, to obtain specification (3). Parameter $\varphi$ captures now the partial effect of trust in government, $t_{i}$, on support for redistribution, given the perception of corruption impunity, while $\gamma /$ is the direct effect of perceived corruption impunity on support for redistribution — which includes all other possible mechanisms besides political trust-, given $t_{i}$.

$$
\begin{array}{llll}
y_{i}^{*}=x_{1 i} \beta_{1}+c_{i} \gamma \prime+t_{i} \varphi+\varepsilon_{1 i}, & y_{i}=1 & \text { if } y_{i}^{*}>0, & 0 \text { otherwise } \\
c_{i}^{*}=x_{2 i} \beta_{2}+t_{i} \delta+\varepsilon_{2 i}, & c_{i}=1 & \text { if } \quad c_{i}^{*}>0, & 0 \text { otherwise }
\end{array}
$$

Now, the (negative) relationship between corruption impunity and trust in the government could capture factors other than individual's expectations about the budget share being drained from public policies. In the context of Latin America, one salient factor is poor state capacity and its consequences in terms of free-riding, tax evasion, or crime. Here, our controls for trustworthiness,

\footnotetext{
36 The error terms are assumed to be correlated within clusters, but uncorrelated across clusters. Failure to control for within-cluster error correlation can lead to very misleadingly small standard errors, and consequent misleadingly large $t$-statistics and low $p$-values. Given the sampling design of the Americas Barometer, following Cameron and Miller (2015) we cluster at the level of the primary sampling unit, this is, the main regions in which each country's sample is stratified.

37 See Wooldridge $(2010,597)$. For this test, we estimate $c_{i}$ using maximum likelihood estimation. Under the assumption that the distribution of $\epsilon_{1 i} \mid x_{1 i}$ follows a probit model, the standardized residuals are defined according to the following formula: $e=\frac{\left(c_{i}-\Phi\left[x_{2 i} \beta_{1}\right] \phi\left[x_{2 i} \beta_{1}\right]\right)}{\Phi\left(x_{2 i} \beta_{2}\right)\left[1-\Phi\left(x_{2 i} \beta_{2}\right)\right]}$.
} 
Table 5

Perception of Corruption and Trust in Government.

\begin{tabular}{|c|c|c|c|c|c|c|c|c|c|}
\hline & \multicolumn{3}{|c|}{ Narrowest Def. Trust ${ }^{(1)}$} & \multicolumn{3}{|c|}{ Wider Def. Trust ${ }^{(2)}$} & \multicolumn{3}{|c|}{ Widest Def. Trust ${ }^{(2)}$} \\
\hline & Coef. & & $(z)$ & Coef. & & $(z)$ & Coef. & & $(z)$ \\
\hline Corruption impunity & -0.128 & **** & $(-26.21)$ & -0.245 & **** & $(-32.93)$ & -0.354 & **** & $(-37.09)$ \\
\hline \multicolumn{10}{|c|}{ Economic situation w.r.t 12 months ago: Better (ref.) } \\
\hline Same & -0.040 & $* * *$ & $(-9.38)$ & -0.049 & $* * *$ & $(-8.23)$ & -0.062 & $* * *$ & $(-9.08)$ \\
\hline Worse & -0.064 & $* * *$ & $(-12.99)$ & -0.092 & $* * *$ & $(-13.65)$ & -0.121 & $* * *$ & $(-14.49)$ \\
\hline \multicolumn{10}{|c|}{ People in this community are generally: Untrustworthy (Ref.) } \\
\hline Somewhat trustworthy & -0.016 & $* *$ & $(-2.51)$ & -0.007 & & $(-0.93)$ & 0.024 & $* * *$ & $(2.94)$ \\
\hline Not very trustworthy & -0.018 & **** & $(-2.68)$ & 0.001 & & $(0.14)$ & 0.052 & $* * *$ & $(6.31)$ \\
\hline Very trustworthy & 0.020 & $* * *$ & $(3.22)$ & 0.044 & $* * *$ & $(5.45)$ & 0.088 & $* * *$ & $(8.77)$ \\
\hline Non-civic behaviour & -0.016 & **** & $(-3.66)$ & -0.019 & $* * *$ & $(-3.02)$ & -0.029 & $* * *$ & $(-4.91)$ \\
\hline Victim of crime & -0.007 & $*$ & $(-1.90)$ & -0.012 & **** & $(-2.69)$ & -0.014 & $* * *$ & $(-2.69)$ \\
\hline Female & 0.002 & & $(0.47)$ & -0.001 & & $(-0.17)$ & 0.001 & & $(0.22)$ \\
\hline White or Mestizo & -0.008 & & $(-1.59)$ & -0.004 & & $(-0.60)$ & 0.002 & & $(0.26)$ \\
\hline Age & 0.001 & $* * *$ & $(7.65)$ & 0.001 & $* * *$ & $(6.99)$ & 0.001 & $* * *$ & $(4.62)$ \\
\hline Has children & 0.011 & $* * *$ & $(2.88)$ & 0.011 & $* *$ & $(2.21)$ & 0.009 & & $(1.57)$ \\
\hline Catholic & 0.004 & & $(0.94)$ & 0.007 & & $(1.41)$ & 0.009 & * & (1.69) \\
\hline \multicolumn{10}{|c|}{ Labour Status: Worker in private sector (ref.) } \\
\hline Inactive & -0.001 & & $(-0.38)$ & -0.006 & & $(-1.05)$ & -0.012 & * & $(-1.72)$ \\
\hline Unemployed & -0.009 & & $(-1.54)$ & -0.008 & & $(-0.91)$ & -0.009 & & $(-0.95)$ \\
\hline Worker in public sector & 0.017 & $* *$ & $(2.17)$ & 0.031 & $* * *$ & $(3.32)$ & 0.036 & $* * *$ & $(3.43)$ \\
\hline Employer or entrepreneur & 0.022 & $*$ & $(1.82)$ & 0.001 & & $(0.09)$ & -0.006 & & $(-0.36)$ \\
\hline Self-employed & -0.004 & & $(-0.82)$ & -0.012 & $*$ & $(-1.82)$ & -0.006 & & $(-0.82)$ \\
\hline News daily & 0.019 & **** & $(5.48)$ & 0.032 & *** & $(7.49)$ & 0.021 & $* * *$ & $(3.67)$ \\
\hline \multicolumn{10}{|l|}{ Wealth index: Quintile 1 (ref.) } \\
\hline Quintile 2 & -0.012 & $* * *$ & $(-3.16)$ & -0.012 & **** & $(-2.36)$ & 0.002 & & $(0.28)$ \\
\hline Quintile 3 & -0.019 & $* * *$ & $(-4.07)$ & -0.021 & $* * * *$ & $(-3.88)$ & -0.014 & $* * *$ & $(-2.13)$ \\
\hline Quintile 4 & -0.021 & $* * *$ & $(-3.61)$ & -0.030 & $* * *$ & $(-4.63)$ & -0.020 & $* * *$ & $(-2.91)$ \\
\hline Quintile 5 & -0.027 & **** & $(-4.42)$ & -0.033 & **** & $(-4.37)$ & -0.026 & $* * *$ & $(-3.20)$ \\
\hline Education (years) & -0.005 & $* * *$ & $(-10.60)$ & -0.005 & $* * *$ & $(-7.58)$ & -0.003 & $* * *$ & $(-3.97)$ \\
\hline \multicolumn{10}{|c|}{ City size: Capital or big city (ref.) } \\
\hline Medium city & 0.002 & & $(0.35)$ & 0.010 & & (1.07) & -0.003 & & $(-0.40)$ \\
\hline Small city & 0.006 & & $(1.21)$ & 0.018 & $* * *$ & $(2.48)$ & 0.005 & & $(0.58)$ \\
\hline Rural & 0.009 & & $(1.50)$ & 0.019 & **** & $(2.37)$ & 0.008 & & $(0.83)$ \\
\hline$R^{2}$ & 0.172 & & & 0.183 & & & 0.196 & & \\
\hline Observations & 55,210 & & & 55,210 & & & 55,210 & & \\
\hline Pseudo Log Likelihood & $-14,863.8$ & & & $-22,424.6$ & & & $-26,458.1$ & & \\
\hline
\end{tabular}

Notes: Average marginal effects of probit models where the dependent variable measures trust in government. Three definitions of trust in government are used:

(1) Narrowest definition: Trust in government takes value 1 if respondents report the maximum score of 7 to the question "To what extent do you trust the national government?".

(2) Wider definition: Trust in government takes value 1 if respondents report scores of 6 or 7 -in a scale from 1 (little) to 7 (a lot)- to the question mentioned in this table note (1).

(3) Widest definition: Trust in government takes value 1 if respondents report a score between 5 and 7 to the question mentioned in this table note (1).

Corruption impunity equals 1 if the respondent reports values between 1 and 3 (out of 7) to the question "To what extent would you say the current administration combats government corruption?". All regressions include fixed effects at region and year level, as well as region-year interaction terms, and the same controls as in column (3) in Table 3. z-statistics in parenthesis. Standard errors are clustered at region level.

$* * *$ significant at 1 per cent; ** significant at 5 per cent; * significant at 10 per cent.

civicness, and crime victimization, together with the set of year/country fixed effects should minimize the extent to which the variable trust in government is related to these elements of poor state capacity.

To measure trust in government we use a dummy variable that takes value one if respondents report a score of 7 -in a scale from 1 (little) to 7 (a lot) — to the following question: "To what extent do you trust the national government?" and zero otherwise. According to this variable, 12.4 per cent of individuals would 'trust the government'. Using wider criteria to define the set of individuals who trust the government does not change our main results - see Table $6 .{ }^{38}$

We first check whether perceived corruption impunity brings about distrust in government institutions. Table 5 reports estimates of a simple probit regressions of our three definitions of the variable trust in the government on perceived corruption impunity and the same set of controls as in Table 3 -that estimates equation (1), and suggests that indeed perception of corruption impunity is

\footnotetext{
38 That is, the causal positive impact of corruption impunity increases when the variable trust in government is included in the regression, as suggested by the model, regardless of the definition of the latter. In particular results are robust to assigning value one if individuals report 6 or 7 to the survey question, which includes a share of the sample, 26.4 per cent, or to assigning value one only if respondents answer between 5 and 7 to the survey question, which includes nearly half (45 per cent) the sample.
} 
Table 6

Effect of Perception of Corruption Impunity on Support for Redistribution Net of Trust in Government.

\begin{tabular}{|c|c|c|c|c|}
\hline & \multicolumn{2}{|c|}{ Excluding Trust } & \multirow{2}{*}{\multicolumn{2}{|c|}{$\frac{\text { Including Trust }}{\text { Narrowest Definition of Trust }{ }^{1}}$}} \\
\hline & \multirow[b]{2}{*}{ Corruption } & \multirow[b]{2}{*}{ Redistribution } & & \\
\hline & & & Corruption & Redistribution \\
\hline Corruption impunity is high & & $\begin{array}{l}0.199^{* * *} \\
(2.29)\end{array}$ & & $\begin{array}{l}0.239^{* * *} \\
(3.16)\end{array}$ \\
\hline Trust in Government & & & $\begin{array}{l}-0.288^{* * *} \\
(-27.00)\end{array}$ & $\begin{array}{l}0.121^{* * * *} \\
(7.18)\end{array}$ \\
\hline Individual bribe victimization & $\begin{array}{l}0.046^{* * *} \\
(6.20)\end{array}$ & & $\begin{array}{l}0.043^{* * * *} \\
(6.05)\end{array}$ & \\
\hline Fisher's $z$ transformed correlation & & $\begin{array}{l}-0.271^{*} \\
(-1.63)\end{array}$ & & $\begin{array}{l}-0.317^{\text {**** }} \\
(-2.07)\end{array}$ \\
\hline Walt test of $\rho=0$ & $(2.65,0.10)$ & & $(4.27,0.04)$ & \\
\hline Observations & 55,210 & & 55,210 & \\
\hline \multirow[t]{4}{*}{ Pseudo Log Likelihood } & $-60,483.8$ & & $-59,352.2$ & \\
\hline & \multicolumn{4}{|c|}{ Including Trust } \\
\hline & \multicolumn{2}{|c|}{ Wider Definition of Trust $^{(2)}$} & \multicolumn{2}{|c|}{ Widest Definition of $\operatorname{Trust}^{(3)}$} \\
\hline & Corruption & Redistribution & Corruption & Redistribution \\
\hline Corruption impunity is high & & $\begin{array}{l}0.244^{* * * *} \\
(3.25)\end{array}$ & & $\begin{array}{l}0.337^{* * * *} \\
(5.69)\end{array}$ \\
\hline Trust in Government & $\begin{array}{l}-0.318^{* * * *} \\
(-32.24)\end{array}$ & $\begin{array}{l}0.058^{* * * *} \\
(4.35)\end{array}$ & $\begin{array}{l}-0.357^{* * * *} \\
(-37.20)\end{array}$ & $\begin{array}{l}0.18^{* *} \\
(2.34)\end{array}$ \\
\hline Individual bribe victimization & $\begin{array}{l}0.038^{* * *} \\
(5.30)\end{array}$ & & $\begin{array}{l}0.032^{* * * *} \\
(5.01)\end{array}$ & \\
\hline Fisher's $z$ transformed correlation & & $\begin{array}{l}-0.271^{*} \\
(-1.63)\end{array}$ & & $\begin{array}{l}-0.317^{* * * *} \\
(-2.07)\end{array}$ \\
\hline Walt test of $\rho=0$ & $(4.43,0.03)$ & & $(11.37,0.00)$ & \\
\hline Observations & 55,210 & & 55,210 & \\
\hline Pseudo Log Likelihood & $-58,487.0$ & & $-57,461.0$ & \\
\hline
\end{tabular}

Notes: Average marginal effects of recursive bivariate probit models where the dependent variables equal 1 if the respondent strongly agrees with the statement "Government should implement strong policies to reduce income inequality" and if the respondent reports values between 1 and 3 (out of 7) to the question "To what extent would you say the current administration combats government corruption?". All regressions include fixed effects at region and year level, as well as region-year interaction terms, and the same controls as in column (3) in Table 3. $z$-statistics in parenthesis. Standard errors are clustered at region level.

(1) Trust in government takes value 1 if respondents report the maximum score of 7 to the question "To what extent do you trust the national government?".

(2) Trust in government takes value 1 if respondents report scores of 6 or 7 -in a scale from 1 (little) to 7 (a lot)- to the question mentioned in this table note (1).

(3) Trust in government takes value 1 if respondents report a score between 5 and 7 to the question mentioned in this table note (1).

(4) The first figure reports the value of the $\chi^{2}(1)$ statistic, while the second figure reports $\operatorname{Prob}>\chi^{2}(1)$.

*** significant at 1 per cent; ** significant at 5 per cent; * significant at 10 per cent.

inversely correlated with trust in government. In particular, believing that there is corruption impunity reduces the probability of trusting the government by between 12.8 and 35.4 percentage points, depending on how we define trust in government.

We can now test whether including trust in government in our baseline model (2) increases the positive effect of perceived corruption impunity on support for redistribution. This is precisely what equations in (3) do, and estimates of the variables of interest are shown in Table 6. For comparative purposes, Table 6 also includes estimates of the baseline model (2) in the first two columns of the upper panel. ${ }^{39}$

As predicted by our model, the estimates of Table 6 suggest a direct positive effect of trust in government on preference for redistribution, and also show how the inclusion of trust in government increases the positive effect of perceived corruption impunity on support for redistribution. The larger coefficient estimate of interest obtained in the three specifications that include the variable trust in government is statistically significantly different (with $p$-value $<0.000$ ) from the baseline coefficient estimate of perceived corruption impunity.

39 A new baseline model is estimated because sample size is different due to missing values in the trust in government variable. 
This strategy, however, is not free of endogeneity concerns. These effects should be interpreted with caution because they only identify causal mediation effects under the sequential ignorability assumption (Imai et al., 2010). ${ }^{40}$ Reassuringly, our results are in line with other studies on the relationship between trust in government and individual demand for redistribution. E.g. Yamamura (2014) finds that in Japan, a culturally homogeneous society, people are both likely to express preferences for income redistribution and to perceive their tax burden as low when trust in government in their residential area is high. Marr and Ming (2014) show that it was the loss of confidence in government during the Great Recession following the financial crisis in 2008 that caused a generalized drop in the demand for redistribution. ${ }^{41}$

\section{Additional robustness checks}

In this section we check the robustness of our key findings. First, in Section 6.1 we use a different variable to capture individual's corruption perception. Instead of perceptions of corruption impunity, we employ a variable of perceptions of corruption. Then, in Section 6.2, we employ an alternative survey question to capture people's support for redistribution, which asks about who should be responsible to ensure the wellbeing of individuals.

\subsection{Alternative variable of corruption perceptions}

Our main results reported in Section 5 use individual's perception of corruption impunity as our empirical measure of $\pi$. This section shows that our findings are robust to using a different variable to empirically approximate $\pi$ : A dummy variable that equals one if respondents deem that corruption among public officials is very common. This variable measures individual's perception of corruption directly and it is thus less faithful to the way we theoretically model corruption perceptions than our baseline variable of corruption impunity, as it does not ask about fighting corruption. The correlation between the two variables (.16) shows that they capture different aspects of individuals' perceptions on corruption. As Figure A4 shows, while in some countries such as Uruguay and Argentina, the sample share reporting high levels of corruption and impunity perceptions is similar, in others these shares differ -e.g. in Colombia the share reporting high impunity is much lower than the share reporting corruption being very common. ${ }^{42}$

The results, reported in Table A7 in the Online Appendix, corroborate the positive overall effect of perceived corruption, and the negative bias introduced by the endogeneity of corruption perceptions. The size of the impact is very similar to the effect of perceived corruption impunity, when endogeneity is dealt with: Perceiving corruption as very common increases support for redistribution by 19 percentage points. Online Appendix A2 shows that linear probability models and addressing the endogeneity of perceived corruption with instrumental variables yields results which are consistent with the bivariate probit estimates. Finally, the inclusion of the variable trust in government in the baseline model reveals that the negative channel predicted by the theoretical model is also present when the variable corruption perceptions is used - see Table A8 in the Online Appendix.

\subsection{Measuring support for redistribution differently}

Preferences for redistribution are meant to capture people's views about the role of the state in altering the distribution of income (and wealth) originating in the markets. The question we use certainly has this emphasis. We test the robustness of our results to using an alternative question, which measures the respondents' agreement with greater levels of state responsibility for provision of welfare.

More precisely, the question reads "The government, rather than individuals, is the main responsible in ensuring the well-being of the people. To what extent do you agree or disagree with this statement?" 43 Possible responses range from 1 to 7 , where ' 1 ' means "strongly disagree" and '7' means "strongly agree", so higher values indicate increasing support for redistribution. As for the benchmark question above, the distribution of the level of agreement with the statement within each country is clearly negatively skewed as most of the respondents express the highest levels of agreement. ${ }^{44}$ For this reason, and for comparative purposes,

\footnotetext{
40 This means that not only perception of corruption impunity should be conditionally independent of unobservables $\varepsilon_{i}$, given covariates $x_{i}$, but also that the mediator variable (trust in government) should be conditionally independent of unobservables $\varepsilon_{i}$, given background covariates $x_{i}$ and $c_{i}$. As in the case of perceived level of corruption impunity, the association between individuals' trust in government and their willingness to support state intervention may be attributed to some common but unobserved factors.

A way to deal with this problem would be to estimate a recursive system which allows for correlation of unobserved determinants of corruption impunity perception, trust in government, and support for redistribution. Identification in this model, however is difficult, as it is challenging to find a valid exclusion restriction, that is, a variable that affects trust in government, and does not affect directly neither the perception of corruption impunity nor support for redistribution.

41 Several papers have shown that trust positively affects the size of the welfare state. The only studies that address the endogeneity issue between trust and the size of welfare states are the cross-country by Bergh and Bjørnskov (2011) and Bjørnskov and Svendsen (2013) and a within-country study of Italy by Camussi et al. (2018). The instruments used by Bergh and Bjørnskov (2011) are: a grammar rule indicating if the country's language allows the personal pronoun to be dropped, the average temperature in the coldest month of the year, and the existence of monarchic institutions. Bjørnskov and Svendsen (2013) instrument current trust levels in a given country by "ancestral trust", which is the average trust level currently observed among US citizens whose ancestors came from that country.

42 We refer the reader to Section 3 for further details about the motivation, definition, and basic descriptive statistics of this variable.

43 In the original (Spanish), the question is: El Estado (gentilicio), más que los individuos, debería ser el principal responsable de asegurar el bienestar de la gente. ¿Hasta qué punto está de acuerdo o en desacuerdo con esta frase?

44 Details can be obtained from the authors upon request.
} 
we collapse the seven response categories to a binary variable, taking value 1 if the individual reports strong agreement with redistribution (i.e. her response is 7), and 0 otherwise. In this case, we use a very similar sample to the previous one (70,564 observations) and obtain almost the same results in univariate and bivariate probit models as in Section 5. First, as can be observed at the bottom of Table A9 in the Online Appendix, the sign of the estimated Fisher's $z$ transformed correlation in the bivariate model is negative, being significantly different from zero at 1 per cent. Thus, once again we can reject the hypothesis that errors in both equations are independent. In addition, the estimated marginal effect of perceived corruption impunity on the probability to strongly support redistributive policies from the bivariate probit model is 33.1 percentage points, larger than the result we obtained with the main support for redistribution question (see Table 3), and five times as large as the estimate from the univariate model. Also, support for redistribution decreases with the wealth level as predicted by our model.

As we did with our baseline dependent variable in Online Appendix A2, we also employ a linear probability model and an instrumental variable estimator (using individual bribery victimization as instrument) to further explore the effect of corruption perceptions on our alternative dependent variable. The estimates from this model, reported in Online Appendix Table A10 yield the same results as the uni- and bivariate probit models. The marginal effect of perceived corruption on preferences for redistribution is positive and more than doubles when endogeneity is corrected. As far as the instrument is concerned, all the tests in Online Appendix Table A11 confirm that perception of corruption is indeed an endogenous variable and that our instrument is not weak.

\section{Concluding remarks}

In this paper we argue that implemented distributional policies do not necessarily reflect people's true individual demand for redistribution. We study how perceived corruption affects individual support for redistribution in a sample of 18 countries in Latin America using a model to guide our empirical analysis. Economists have suggested different channels through which corruption can shape individuals' preferences for redistribution. While all these channels might be relevant, the nature of our data pushed us to work with a theoretical model which only captures two of them ${ }^{45}$ : (i) Corruption undermines trust in government and therefore reduces people's support for redistribution. (ii) Corruption reduces relative wealth of the disadvantaged, which leads to a higher demand for redistribution. These two opposing forces make it impossible to sign the net effect of perceived corruption on redistribution a priori.

Latin America is of special interest, since this region suffers from high levels of inequality and weak institutions, where democratic systems are still consolidating and corruption is widespread. It is a region that has not been studied before and is sufficiently different from the average OECD country that findings for Latin America might be different to previous findings. The paper shows that this is indeed the case. Our findings take due account of the potential endogeneity between perceived corruption and support for redistribution, and are robust to using different measures of corruption perception and of preferences for redistribution, that focus on different implications of redistributive policies and that have been found to affect the support people report for redistribution (Alesina and La Ferrara, 2005). Our novel empirical findings suggest that perceiving corruption in the public sector increases people's support for redistribution in Latin America. We also find evidence for the trust channel, that turns out to be less important than the wealth channel. The Latin American experience is particularly powerful for our starting point. While corruption increases the individual demand for redistribution, there is no significant relationship between the size of the actual welfare state and corruption in Latin America. ${ }^{46}$ The size of the welfare state is therefore uninformative about what people really want. More research is needed to fully understand why and when this happens.

\section{Declaration of competing interest}

The authors declare that they have no known competing financial interests or personal relationships that could have appeared to influence the work reported in this paper.

\section{Data availability}

Data will be made available on request.

\footnotetext{
45 In particular, our data does not allow us to examine fairness concerns nor rent-seeking motives for favouring more redistribution if corruption is more wide-spread (Alesina and Angeletos, 2005). Our results seem to suggest that rent-seeking motives do not play an important role in our data since we estimate a negative relation between wealth levels and the preferences for redistribution.

46 Using our LAPOP sample, we obtain point OLS estimates of this relationship from regressions that are negative but not statistically significant. This evidence is available upon request.
} 


\section{Acknowledgements}

We thank the Latin American Public Opinion Project (LAPOP) and its major supporters (the United States Agency for International Development, the United Nations Development Program, the Inter-American Development Bank, and Vanderbilt University) for making the data available. We would also like to thank Anastasia Litina, Hannes Mueller, Gianmarco León, and Juan Pablo Nicolini for their comments and suggestions as well as participants at the 6th ECINEQ Meeting in Luxembourg. Xavier Ramos acknowledges financial support of projects PID2019-104619RB-C43 (Ministerio de Ciencia e Innovación, Spain) and 2017SGR-1571 (Generalitat de Catalunya, Spain). Esther Hauk acknowledges financial support from the Spanish Agencia Estatal de Investigación (AEI), through the Severo Ochoa Programme for Centers of Excellence in R\&D (Barcelona School of Economics CEX2019-000915-S), and through CICYT project number ECO2015-67171-P (MINECO/FEDER), and from the Spanish Ministry of Science, Innovation and Universities through project PGC2018-097898-B-100 MCIU/AEI/FEDER and from the government of Catalonia under project 2017 SGR1571.

\section{Appendix A. Supplementary data}

Supplementary material related to this article can be found online at https://doi.org/10.1016/j.ejpoleco.2021.102174.

\section{References}

Acemoglu, D., 2005. Politics and economics in weak and strong states. J. Monetary Econ. 52, 1199-1226.

Acemoglu, D., Tichhi, D., Vindigni, A., 2011. Emergence and persistence of inefficient states. J. Eur. Econom. Assoc. 9 (2), $177-208$.

Ait Bihi Ouali, L., 2020. Effects of signalling tax evasion on redistribution and voting preferences: Evidence from the panama papers. PLOS ONE 15 (3), e0229394. Alesina, A., Angeletos, G.M., 2005. Corruption, inequality, and fairness. J. Monetary Econ. 52 (7), $1227-1244$.

Alesina, A., Giuliano, P., 2011. Preferences for redistribution. In: A. Bisin, M.O. Jacson (Ed.), Handbook of Social Economics. North Holland, San Diego, CA: North-Holland, pp. 93-131.

Alesina, A., La Ferrara, E., 2005. Preferences for redistribution in the land of opportunities. J. Public Econ. 89 (5-6), 897-931.

Algan, Y., Cahuc, P., Sangnier, M., 2016. Trust and the welfare state: The twin peaks curve. Econ. J. 126, 861-883.

Altamirano, M., Berens, S., Ley, S., 2020. The welfare state amid crime: How victimization and perceptions of insecurity affect social policy preferences in latin america and the caribbean. Politics Soc. 48 (3), 389-422.

Ardanaz, M., 2009. Preferences for redistribution in the land of inequalities. In: Mini-APSA Research Paper. Columbia University. Available at: http://www. columbia.edu/cu/polisci/pdf-files/miniapsa_ardanaz.pdf.

Arellano, M., 2007. Binary models with endogenous explanatory variables. In: Class Notes CEMFI (Center for Monetary and Financial Studies) November 7, 2007 Revised: January 21, 2008. http://www.cemfi.es/ \{126\} arellano/binary-endogeneity.pdf.

Balafoutas, L., 2011. How much income redistribution? An explanation based on vote-buying and corruption. Public Choice 146 (1), $185-203$.

Bergh, A., Bjørnskov, C., 2011. Historical trust levels predict the current size of the welfare state. Kyklos 64 (1), 1-19.

Bird, R., Martinez-Vazquez, J., Torgler, B., 2008. Tax effort in developing countries and high income countries: The impact of corruption, voice and accountability. Econ. Anal. Policy 1 (38), 55-71.

Bjørnskov, C., Svendsen, G., 2013. Does social trust determine the size of the welfare state? Evidence using historical identification. Public Choice 157 (1), 269-286.

Borisova, E., Govorun, A., Ivanov, D., Levina, I., 2018. Social capital and preferences for redistribution to target groups. Eur. J. Political Econ. 54, 56-67.

Cameron, C., Miller, D.L., 2015. A practitioner's guide to cluster-robust inference. J. Hum. Resour. 50 (2), $317-372$.

Camussi, Silvia, Mancini, Laura, Anna., Tommasino, Pietro., 2018. Does trust influence social expenditures? Evidence from local governments. Kyklos 71 (1), 59-85.

Castañeda, N., Doyle, D., Schwartz, C., 2020. Opting out of the social contract: Tax morale and evasion. Comp. Political Stud. 53 (7), $1175-1219$.

Corneo, G., Grüner, H.P., 2002. Individual preferences for political redistribution. J. Public Econ. 83, 83-107.

Cramer, B.D., Kaufman, R.R., 2011. Views of economic inequality in Latin America. Comp. Political Stud. 44 (9), $1206-1237$.

Daniele, G., Geys, B., 2015. Interpersonal trust and welfare state support. Eur. J. Political Econ. 39, 1-12.

Daude, C., Melguizo, A., 2010. Taxation and more representation?: On fiscal policy, social mobility and democracy in Latin America. In: OECD Development Centre Working Papers 294, OECD Publishing.

Di Tella, R., MacCulloch, R., 2006. Corruption and the demand for regulating capitalists. In: Rose-Ackerman, S. (Ed.), International Handbook on the Economics of Corruption. Edward Elgar Publishing., pp. 352-380, Chapter 12.

Di Tella, R., MacCulloch, R., 2009. Why doesn't capitalism flow to poor countries? Brook. Pap. Econ. Act. 40 (1), $285-332$.

Docquier, F., Tarbalouti, E., 2001. Bribing votes: A new explanation to the inequality-redistribution puzzle in LDC's. Public Choice 108 (3/4), 259-272.

Dong, D., Togler, D., 2011. Democracy, property rights, income inequality and corruption. In: Working paper 08.2011 Fondazione Eni Enrico Mattei..

Dusha, E., 2015. Persistent inequality, corruption and factor productivity. In: Economics Working Paper No 319, University of Chile.

Filmer, D., Pritchett, L.H., 2001. Estimating wealth effect without expenditure data or tears: An application to educational enrollments in the sates of India. Demography 38 (1), 115-132.

Foellmi, R., Oechslin, M., 2007. Who gains from non-collusive corruption? J. Dev. Econ. 82, 95-119.

Galindo, A.J., Schiantarelli, F. (Eds.), 2003. Credit Constraints and Investment in Latin America. Inter-American Development Bank., Washington, D.C.

Gasparini, L., Sosa, W., Marchionni, M., Olivieri, S., 2008. Income, deprivation, and perceptions in Latin America and the Caribbean: New evidence from the gallup world poll. In: Labor and Social Affairs. CEDLAS, In: Latin American Research Network, Inter-American Development Bank, and Center for the Study of Distribution, La Plata, Argentina.

Gaviria, A., 2008. Social mobility and preferences for redistribution in Latin America. Economía 8 (1), 55-96.

Gehlbach, S., 2006. The consequences of collective action: An incomplete-contracts approach. Am. J. Political Sci. 50, 02-823.

Goñi, E., Lopez, H., Serven, L., 2008. Fiscal redistribution and income inequality in Latin America. In: The World Bank. Policy Research working paper ; no. WPS 4487.

Greene, W., Hensher, D., 2009. Modeling Ordered Choices: A Primer and Recent Developments. Cambridge University Press, Cambridge.

Gupta, S., Davoori, H., Alonso-Terme, R., 2002. Does corruption affect income inequality and poverty? Econ. Gov. 3, 23-45.

Han, S., Vytlacil, E.J., 2017. Identification in a generalization of bivariate probit models with dummy endogenous regressors. J. Econometrics 199 , 63-73.

Imai, K., Keele, L., Yamamoto, T., 2010. Identification, inference and sensitivity analysis for causal mediation effects. Statist. Sci. 25 (1), $51-71$.

Kaufmann, D., Kraay, A., Mastruzzi, M., 2009. Governance matters VIII: aggregate and individual governance indicators, 1996-2008. In: World Bank Policy Research Working Paper No. 4978.. 
Kolenikov, S., Angeles, G., 2009. Socioeconomic status measurement with discrete proxy variables: Is principal component analysis a reliable answer? Rev. Income Wealth 55 (1), 128-165.

Kuziemko, I., Norton, M., Saez, E., S., Stantcheva, 2015. How elastic are preferences for redistribution? Evidence from randomized survey experiments. Amer. Econ. Rev. 105 (4), 1478-1508.

Leon, G., 2014. Strategic redistribution: The political economy of populism in Latin America. Eur. J. Political Econ. 34, 39-51.

Levine, R., 1997. Financial development and economic growth: Views and agenda. J. Econ. Lit. XXXV, 668-726.

Li, C., Poskitt, D.S., Zhao, X., 2019. The bivariate probit model, maximum likelihood estimation, pseudo true parameters and partial identification. J. Econometrics 209, 94-113.

Mares, I., 2005. Social protection around the world: External insecurity, state capacity, and domestic political cleavages. Comp. Politial Stud. 38, 623-651.

Mares, I., Carnes, M.E., 2009. Social policy in developing countries. Annu. Rev. Political Sci. 12, 93-113.

Marr, C., Ming, C., 2014. Understanding changes in attitudes towards redistribution and government after the great recession. In: SSRN Working Paper https://doi.org/10.2139/ssrn.2184298.

Mauro, P., 1998. Corruption and the composition of government expenditure. J. Public Econ. 69, $263-279$.

Melgar, N., Rossi, M., Smith, T., 2010. The perception of corruption. Int. J.Public Opin. Res. 22, $120-131$.

Monfardini, C., Radice, R., 2008. Testing exogeneity in the bivariate Probit model: A Monte Carlo study. Oxf. Bull. Econ. Statist. 70 (2), $271-282$.

Morgan, J., Kelly, N.J., 2010. Explaining public attitudes toward fighting inequality in Latin America. Poverty Public Policy 2 (3), 79-111.

OECD, 2009. Latin American Economic Outlook 2009. Development Centre of the Organisation for Economic Co-Operation and Development.

Rehm, P., 2011. Social policy by popular demand. World Politics 63, 271-299.

Rivers, D., Vuong, Q., 1988. Limited information estimators and exogeneity tests for simultaneous probit models. J. Econometrics 39, 347-366.

Robinson, J., 2008. The political economy of redistributive policies. In: Research for Public Policy Inclusive Development ID-09-2009. United Nations Development Programme Regional Bureau for Latin America and the Caribbean..

Rodríguez-Castelán, C., López-Calva, L.F., Lustig, N., Valderrama, D., 2016. Understanding the Dynamics of Labor Income Inequality in Latin America. The World Bank..

Rose-Ackerman, S., 1999. Corruption and Government: Causes, Consequences and Reform. Cambridge University Press, New York.

Rothstein, B., Uslaner, E.M., 2005. All for all: equality, corruption, and social trust. World Politics 58, 41-72.

Rueda, D., Stegmueller, D., 2016. The externalities of inequality: Fear of crime and preferences for redistribution in Western Europe. Am. J. Political Sci. 60 (2), $472-489$.

Sanchez, A., Goda, T., 2018. Corruption and the paradox of redistribution. Soc, Indic. Res. 140 (2), $675-693$.

Tanzi, V., Davoodi, H., 1998. Corruption, public investment, and growth. In: T., Shibata H. Ihori (Ed.), The Welfare State, Public Investment, and Growth. Springer, Tokyo.

Transparency International, 2020. Publications of the corruption perception index. https://www.transparency.org/en/cpi/2020/index/nzl.

Winkelmann, R., 2011. Copula bivariate probit models: with an application to medical expenditures. In: ECON - Working Papers 029, Department of Economics - University of Zurich.

Wooldridge, J.M., 2010. Econometric Analysis of Cross Section and Panel Data, second ed. MIT Press., Cambridge.

World Bank, 2006. World Development Report 2006: Equity and Development. Oxford University Press, Washington D.C., Oxford.

Yamamura, E., 2012. Social capital, household income, and preferences for income redistribution. Eur. J. Political Econ. 28 (4), $498-511$.

Yamamura, E., 2014. Trust in government and its effect on preferences for income redistribution and perceived tax burden. Econ. Gov. 15 (1), 71-100. 